\title{
Safety of early orthopedic surgery in patients with intermediate/ low- or low-risk pulmonary embolism
}

\author{
Ho Cheol Kim ${ }^{1}$, Jin-Han Park ${ }^{2}$, Jong-Min Song ${ }^{3,4}$, Jae-Joon Hwang ${ }^{5}$, Sang-Bum Hong ${ }^{1,4}$, Yeon-Mok Oh ${ }^{1}$, \\ Sang-Do Lee ${ }^{1}$, Jae Seung Lee ${ }^{1,4}$ \\ ${ }^{1}$ Department of Pulmonary and Critical Care Medicine, Asan Medical Center, University of Ulsan College of Medicine, Seoul, South Korea; \\ ${ }^{2}$ Department of Internal Medicine, Haeundae Paik Hospital, Inje University College of Medicine, Busan, Korea; ${ }^{3}$ Division of Cardiology, ${ }^{4}$ Center for \\ Pulmonary Hypertension and Venous Thrombosis, Asan Medical Center, University of Ulsan College of Medicine, Seoul, South Korea; ${ }^{5}$ Department \\ of Pulmonary and Critical Care Medicine, Kyung Hee University Hospital at Gangdong, Seoul, Korea \\ Contributions: (I) Conception and design: HC Kim, JH Park, JS Lee; (II) Administrative support: JS Lee, JJ Hwang; (III) Provision of study \\ materials or patients: SB Hong, YM Oh, SD Lee; (IV) Collection and assembly of data: HC Kim, JH Park, JS Lee, JJ Hwang; (V) Data analysis and \\ interpretation: HC Kim, SB Hong, YM Oh, SD Lee, JS Lee; (VI) Manuscript writing: All authors; (VII) Final approval of manuscript: All authors. \\ Correspondence to: Jae Seung Lee, MD, PhD. Department of Pulmonary and Critical Care Medicine, Asan Medical Center, University of Ulsan \\ College of Medicine, 88, Olympic-ro 43-gil, Songpa-gu, Seoul 05505, South Korea. Email: jsdoc1186@daum.net.
}

Background: Preoperative pulmonary embolism (PE) is one of the comorbidities in patients with hip fracture. However, previous studies have not identified the optimal timing of surgery in these patients, who might require early surgery. This study aimed to investigate the safety and clinical feasibility of early surgery in patients with hip fracture and acute $\mathrm{PE}$.

Methods: The medical records of 156 patients with hip fracture, who were suspected to have PE and underwent pulmonary computed tomography angiography at Asan Medical Center from January 2008 to December 2017, were retrospectively reviewed. After excluding patients who were diagnosed with PE during the postoperative period, the baseline characteristics and clinical course were compared between patients preoperatively diagnosed with $\mathrm{PE}$ (PE group) and patients without PE during the hospital stay (non-PE group). Adverse outcomes were evaluated during 3 months postoperatively.

Results: The baseline characteristics were not different between the PE group $(n=90)$ and the non$\mathrm{PE}$ group ( $\mathrm{n}=50)$. All patients in the PE group were classified as having an intermediate/low or low risk according to the European Society of Cardiology guidelines and underwent surgery within 30 days after the PE diagnosis (median duration: 2 days). None of the patients in both groups developed symptomatic venous thromboembolism (VTE) during the follow-up. Moreover, there were no statistically significant differences in major bleeding, clinically relevant nonmajor (CRNM) bleeding, transfusion amount, bleeding site, and length of hospital stay between the PE and non-PE groups.

Conclusions: Our results suggest that early surgery might be a reasonable treatment option in patients with hip fracture and acute PE.

Keywords: Hip fracture; surgery; pulmonary embolism (PE); venous thromboembolism (VTE); safety

Submitted Oct 29, 2019. Accepted for publication Dec 26, 2019.

doi: $10.21037 /$ jtd.2020.01.54

View this article at: http://dx.doi.org/10.21037/jtd.2020.01.54

(c) Journal of Thoracic Disease. All rights reserved. 


\section{Introduction}

Venous thromboembolism (VTE), including deep vein thrombosis (DVT) and pulmonary embolism (PE), is a relatively common condition with increasing incidence and prevalence worldwide (1-3). Although new classes of drugs, such as direct oral anticoagulants (DOACs), have been effectively used for its prevention and treatment $(4,5), \mathrm{VTE}$ is still associated with significant morbidity and mortality (6).

There are several risk factors for the development of VTE. Approximately $20-30 \%$ of all PE events are associated with other factors including trauma, major surgery, and recent immobilization $(7,8)$. Among these identifiable risk factors, fracture that requires surgery is associated with the development of VTE during both the preoperative and postoperative periods (9-11). Generally, it is recommended to postpone elective surgery for a minimum of 2-4 weeks from the acute $\mathrm{PE}$ event because of the high risk of recurrence in the first 4 weeks $(12,13)$. O'Donnell and Kearon reported that discontinuation of anticoagulation within 1 month after acute VTE is associated with a recurrence rate of $>40 \%$ (13). They also recommended preoperative inferior vena cava (IVC) filter insertion if delaying surgery is not feasible (13).

Hip fracture is a representative disease that requires early surgery to reduce mortality and perioperative complications $(14,15)$. However, there are scarce data about the optimal timing of surgery and the clinical course in patients with hip fracture and acute PE. Thus, the current study aimed to evaluate the safety and clinical outcomes of early surgery within 1 month after acute PE in patients with hip fracture.

\section{Methods}

\section{Study population and methods}

We performed a retrospective cohort study at Asan Medical Center, a tertiary referral hospital in Seoul, South Korea. Patients with hip fracture diagnosed from January 2008 to December 2017 and who underwent surgery were screened. Among these patients, only those who were suspected to have $\mathrm{PE}$ and underwent pulmonary computed tomography (CT) angiography were included in this study. After excluding patients who were diagnosed with $\mathrm{PE}$ during the postoperative period, the included patients were classified into two groups: $\mathrm{PE}$ group, which included patients who had been diagnosed with PE before surgery, and the non-PE group, which included patients who had not been diagnosed with PE during the hospital stay. The diagnosis of $\mathrm{PE}$ and
DVT was confirmed with pulmonary CT angiography, lower-extremity venographic CT, and lower-extremity venous Doppler ultrasound. Initially, data on age, sex, body mass index, D-dimer level, history of malignancy, presence of DVT, and echocardiography findings were collected from the electronic medical records of Asan Medical Center. The severity of PE was evaluated using the simplified Pulmonary Embolism Severity Index (PESI) at the time of CT scan (16) and according to the 2014 European Society of Cardiology guidelines (17). The study protocol was approved by the institutional review board of Asan Medical Center (approval no. 2019-0394), and written informed consent was waived owing to the retrospective nature of the study.

\section{Perioperative management}

The perioperative management of patients with acute PE requiring surgery at our institution has been based on a review article by O'Donnell and Kearon (13) and the American College of Chest Physicians guidelines (18). In patients in whom surgery cannot be delayed for $>3$ months after the PE diagnosis, therapeutic dose bridging anticoagulation is recommended. In addition, in patients in whom surgery could not be delayed for $>2$ weeks after the PE diagnosis, preoperative IVC filter insertion is recommended. However, preoperative IVC filter insertion and postoperative anticoagulation were performed on a case-by-case basis according to the decision of the responsible surgeon.

\section{Definition of outcomes}

Adverse outcomes during 3 months after the surgery were evaluated. The primary outcomes in this study were symptomatic recurrent VTE and major bleeding. The secondary outcomes were clinically relevant nonmajor (CRNM) bleeding, amount of perioperative transfusion, length of hospital stay, and perioperative mortality. Major and CRNM bleeding were defined as in previous studies $(19,20)$. Major bleeding was defined as fatal bleeding or surgical-site bleeding that requires a second intervention; overt bleeding with a hemoglobin decrease of $\geq 2 \mathrm{~g} / \mathrm{dL}$ after the surgery or transfusion of $\geq 2$ units of packed red blood cells; or intracranial, intraspinal, intraocular, retroperitoneal, and pericardial bleeding (21). CRNM bleeding was defined as overt bleeding that did not meet the criteria of major bleeding but needed medical attention, unscheduled visits to a medical institution, and discontinuation of anticoagulants, 
Table 1 Baseline characteristics of patients

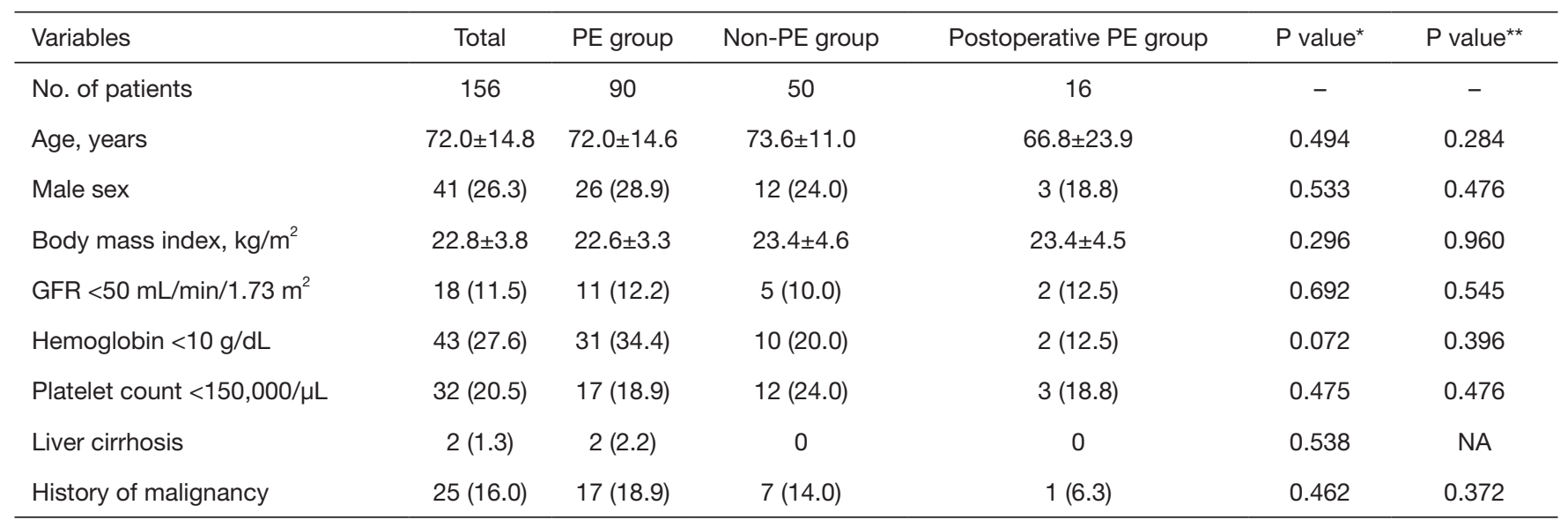

Among the total patients, 16 were diagnosed with PE during the postoperative period. Data are presented as mean \pm standard deviation or number (\%), unless otherwise indicated. *, P value between PE and non-PE group, **, P value between non-PE and postoperative PE group. PE, pulmonary embolism; GFR, glomerular filtration rate, NA, not available.

or resulted in impairment of daily activities (22).

\section{Statistical analysis}

Continuous variables were expressed as mean \pm standard deviation or median (interquartile range), and categorical variables were presented as number (percentage). Continuous variables were compared using the MannWhitney U-test, and categorical variables were compared using the chi-square or Fisher's exact test, as appropriate. All $P$ values were 2 -tailed, with statistical significance set at $\mathrm{P}<0.05$. All statistical analyses were performed using SPSS 20.0 (IBM Corporation, Armonk, NY, USA).

\section{Results}

\section{Clinical characteristics of patients}

A total of 156 patients with hip fracture and who underwent pulmonary CT angiography were identified, of whom 16 patients $(10.3 \%)$ were diagnosed with $\mathrm{PE}$ during the postoperative period (postoperative PE group). Subsequently, 90 patients $(57.7 \%)$ were classified into the PE group and 50 patients $(32.1 \%)$ were classified into the non-PE group. The baseline characteristics of the patients in both groups are presented in Table 1. The mean patient age was 72 years, and $26.3 \%$ of the patients were men. There were no statistical differences in baseline characteristics between the $\mathrm{PE}$ and non-PE groups, non-PE and postoperative $\mathrm{PE}$ groups.

In the PE group, DVT was identified in $38.9 \%$ of patients at the time of $\mathrm{PE}$ diagnosis (Table 2). In these patients, the most common classification of PE was PESI class II (45.6\%), followed by PESI class III (31.1\%) and PESI class I (15.6\%). According to the European Society of Cardiology guidelines, all patients in the PE group were classified as having intermediate/low risk $(38.9 \%)$ or low risk $(61.1 \%)$. With respect to the involved artery level, the segmental pulmonary artery $(47.8 \%)$ was the most frequently involved, followed by the lobar pulmonary artery $(23.3 \%)$ and the subsegmental pulmonary artery (18.9\%). Pulmonary infarction was observed in only 1 patient.

\section{Perioperative management in PE group}

The median duration between PE diagnosis and surgery was 2 days, and all patients in the PE group underwent surgery within 1 month after the PE diagnosis (Table 3). Half of the patients in the PE group underwent IVC filter insertion before surgery. In addition, $64.4 \%$ of the patients in the $\mathrm{PE}$ group received preoperative anticoagulation, with heparin $(45.6 \%)$ as the most commonly used agent. The median operation time was $108 \mathrm{~min}$, and the median time without anticoagulation after surgery was $40 \mathrm{~h}$. About $95.6 \%$ of the patients in the PE group received postoperative anticoagulation, with low molecular weight 
Table 2 Clinical characteristics and pulmonary CT angiography findings of the study patients with pulmonary embolism

\begin{tabular}{|c|c|}
\hline Variables & Total $(n=90)$ \\
\hline \multicolumn{2}{|l|}{ DVT at the time of PE diagnosis } \\
\hline Present & $35(38.9)$ \\
\hline Absent & $34(37.8)$ \\
\hline Unknown & $21(23.3)$ \\
\hline \multicolumn{2}{|l|}{ PESI } \\
\hline Class I & $14(15.6)$ \\
\hline Class II & $41(45.6)$ \\
\hline Class III & $28(31.1)$ \\
\hline Class IV & $6(6.7)$ \\
\hline Class V & $1(1.1)$ \\
\hline \multicolumn{2}{|l|}{ Risk stratification* } \\
\hline High risk & 0 \\
\hline Intermediate/high risk & 0 \\
\hline Intermediate/low risk & $35(38.9)$ \\
\hline Low risk & $55(61.1)$ \\
\hline \multicolumn{2}{|l|}{ Pulmonary CT angiography findings } \\
\hline Single vessel involved & $51(56.7)$ \\
\hline Multiple vessels involved & 39 (43.3) \\
\hline \multicolumn{2}{|l|}{ Artery involved } \\
\hline Pulmonary trunk & 0 \\
\hline Main pulmonary artery & $9(10.0)$ \\
\hline Lobar pulmonary artery & $21(23.3)$ \\
\hline Segmental pulmonary artery & $43(47.8)$ \\
\hline Subsegmental pulmonary artery & $17(18.9)$ \\
\hline Pulmonary infarction & $1(1.1)$ \\
\hline
\end{tabular}

Data are presented as number (\%), unless otherwise indicated. *, risk stratification was performed according to the 2014 European Society of Cardiology guidelines. DVT, deep vein thrombosis; PE, pulmonary embolism; PESI, Pulmonary Embolism Severity Index; CT, computed tomography.

heparin (LMWH) $(41.1 \%)$ as the most commonly used agent.

\section{Clinical course comparison between groups}

More patients in the PE group received postoperative
Table 3 Perioperative management of the study patients with pulmonary embolism

\begin{tabular}{lc}
\hline Variables & Total $(\mathrm{n}=90)$ \\
\hline $\begin{array}{l}\text { Median duration between PE diagnosis and surgery, } \\
\text { days }\end{array}$ & $2[1-4]$ \\
Preoperative IVC filter insertion & $45(50.0)$ \\
Preoperative anticoagulation & \\
Heparin & $41(45.6)$ \\
LMWH & $11(12.2)$ \\
DOAC & $6(6.7)$ \\
Not performed & $32(35.6)$ \\
Duration of operation, min & $108[91-152]$ \\
Time without anticoagulation after surgery, hours & $40[18-71]$ \\
Initial postoperative anticoagulation & \\
Heparin & $23(25.6)$ \\
LMWH & $37(41.1)$ \\
DOAC & $26(28.9)$ \\
Not performed & $4(4.4)$ \\
\hline
\end{tabular}

Data are presented as number (\%) or median [interquartile range], unless otherwise indicated. PE, pulmonary embolism; IVC, inferior vena cava; LMWH, low molecular weight heparin; DOAC, direct oral anticoagulant.

anticoagulation (treatment dose in the PE group, prophylactic dose in the non-PE group) than those in the non-PE group $(95.6 \%$ vs. $54.0 \%, \mathrm{P}<0.001$ ) (Table 4). However, among the study patients, there were no symptomatic recurrent VTE and mortality cases within 3 months. Further, there were no statistically significant differences in major bleeding, CRNM bleeding, transfusion amount, bleeding site, and length of hospital stay between the two groups.

\section{With vs. without IVC filter}

Among the patients in the PE group, those who underwent IVC filter insertion had higher D-dimer levels (median 19.0 vs. $12.1 \mathrm{~g} / \mathrm{mL}, \mathrm{P}=0.021$ ) than those who did not (Table 5). In addition, more patients in the IVC filter group had DVT at the time of $\mathrm{PE}$ diagnosis $(57.8 \%$ vs. $20.0 \%, \mathrm{P}=0.001)$ than those in the non-IVC filter group. However, there were no statistically significant differences in clinical outcomes such as bleeding and length of hospital stay between the IVC 
Table 4 Comparison of clinical course between the PE and non-PE groups

\begin{tabular}{|c|c|c|c|c|}
\hline Variables & Total & PE group & Non-PE group & $P$ value \\
\hline Duration of operation, min & $108[93-140]$ & $108[91-152]$ & $108[96-136]$ & 0.915 \\
\hline Postoperative anticoagulation* & $113(80.7)$ & $86(95.6)$ & $27(54.0)$ & $<0.001$ \\
\hline Time without anticoagulation after surgery, hours & 40 [18-72] & $40[18-71]$ & $40[12-80]$ & 0.779 \\
\hline Perioperative mortality & 0 & 0 & 0 & N.A. \\
\hline \multicolumn{5}{|l|}{ Bleeding } \\
\hline Major bleeding & $27(19.3)$ & $19(21.1)$ & $8(16.0)$ & 0.463 \\
\hline CRNM bleeding & $16(11.4)$ & $12(13.3)$ & $4(8.0)$ & 0.342 \\
\hline Transfusion $>2$ units & $14(32.6)$ & $10(32.3)$ & $4(33.3)$ & \\
\hline \multicolumn{5}{|l|}{ Bleeding site } \\
\hline Operation-site bleeding & $40(28.6)$ & $28(31.1)$ & $12(24.0)$ & 0.372 \\
\hline GI tract bleeding & $2(1.4)$ & $2(2.2)$ & 0 & 0.538 \\
\hline Urinary tract bleeding & $1(0.7)$ & $1(1.1)$ & 0 & $>0.999$ \\
\hline Length of hospital stay, days & $14[9-21]$ & 13 [9-19] & 16 [9-22] & 0.362 \\
\hline
\end{tabular}

Data are presented as mean \pm standard deviation, median [interquartile range], or number (\%), unless otherwise indicated. *, postoperative anticoagulation was administered as a treatment dose in the PE group and as a prophylactic dose in the non-PE group. PE, pulmonary embolism; VTE, venous thromboembolism; N.A., not available; CRNM, clinically relevant nonmajor; Gl, gastrointestinal.

filter group and the non-IVC filter group.

\section{Discussion}

The current study investigated the safety and clinical feasibility of early orthopedic surgery within 1 month in patients with hip fracture and acute PE. Although $21.1 \%$ of patients in the PE group experienced major bleeding during 3 months after surgery, there was no difference in clinical course between the PE and non-PE groups. Our study suggests that early surgery is clinically feasible in patients with intermediate/low- or low-risk PE, when the perioperative management protocol based on the American College of Chest Physicians guidelines is properly applied.

Although previous studies focused on the incidence and prophylaxis of VTE after hip fracture surgery $(10,23,24)$, several studies showed that preoperative VTE is also a common finding in patients with hip fracture (with an incidence ranging from $2.6 \%$ to $62 \%)(11,25-28)$. However, there is no evidence about the timing of surgery in patients with hip fracture with preoperative VTE, especially in PE cases. Patients with VTE have a risk of recurrence, especially in the first 4 weeks (12). Thus, previous studies suggested that elective surgery should be delayed for at least 1 month from VTE diagnosis, as much as possible $(13,29)$. However, previous studies did not consider the type of surgery, which might affect the clinical decision. Generally, hip fracture requires early surgery not only for improving function and mortality (15) but also for reducing complications (14). In addition, Cho et al. showed that patients who were admitted $>72 \mathrm{~h}$ after injury had a higher prevalence of VTE than those who were admitted within $72 \mathrm{~h}$ after the injury (28), which emphasizes the importance of early surgery. Our current study revealed that a proper management strategy might reduce morbidity and mortality in patients with hip fracture and acute PE, especially in lowrisk cases.

In the PE group in the current study, approximately 
Table 5 Baseline characteristics and clinical outcomes according to IVC filter insertion in the PE group

\begin{tabular}{|c|c|c|c|}
\hline \multirow{2}{*}{$\begin{array}{l}\text { Variables } \\
\text { No. of patients }\end{array}$} & \multicolumn{3}{|c|}{ IVC filter group Non-IVC filter group P value } \\
\hline & 45 & 45 & \\
\hline Age, years & $71.6 \pm 15.6$ & $72.4 \pm 13.8$ & 0.791 \\
\hline Male sex & $14(31.1)$ & $12(26.7)$ & 0.642 \\
\hline $\begin{array}{l}\text { Body mass index, } \\
\mathrm{kg} / \mathrm{m}^{2}\end{array}$ & $22.7 \pm 3.2$ & $22.4 \pm 3.4$ & 0.659 \\
\hline D-dimer, $\mathrm{g} / \mathrm{mL}$ & $19.0[8.1-30.2]$ & $12.1[4.4-22.5]$ & 0.021 \\
\hline History of malignancy & $7(15.6)$ & $10(22.2)$ & 0.419 \\
\hline $\begin{array}{l}\text { DVT at the time of PE } \\
\text { diagnosis }\end{array}$ & & & 0.001 \\
\hline Present & $26(57.8)$ & $9(20.0)$ & \\
\hline Absent & $12(26.7)$ & $22(48.9)$ & \\
\hline Unknown & $7(15.6)$ & $14(31.1)$ & \\
\hline $\begin{array}{l}\text { Symptomatic } \\
\text { recurrent VTE }\end{array}$ & 0 & 0 & NA \\
\hline $\begin{array}{l}\text { Perioperative } \\
\text { mortality }\end{array}$ & 0 & 0 & NA \\
\hline \multicolumn{4}{|l|}{ Bleeding } \\
\hline Major bleeding & $10(22.2)$ & $9(20.0)$ & 0.796 \\
\hline CRNM bleeding & $9(20.0)$ & $3(6.7)$ & 0.063 \\
\hline Transfusion & $19(42.2)$ & $12(26.7)$ & 0.120 \\
\hline Transfusion $\leq 2$ units & $15(78.9)$ & $6(50.0)$ & \\
\hline $\begin{array}{l}\text { Transfusion } \\
>2 \text { units }\end{array}$ & $4(21.1)$ & $6(50.0)$ & \\
\hline $\begin{array}{l}\text { Length of hospital } \\
\text { stay, days }\end{array}$ & 14 [9-21] & $12[9-17]$ & 0.455 \\
\hline
\end{tabular}

Data are presented as mean \pm standard deviation, median [interquartile range], or number (\%), unless otherwise indicated. IVC, inferior vena cava; DVT; deep vein thrombosis; VTE, venous thromboembolism; NA, not available; CRNM, clinically relevant nonmajor.

$64.4 \%$ of patients received preoperative anticoagulation and nearly all patients (95.6\%) received postoperative anticoagulation. Although major bleeding occurred in $21.1 \%$ of patients in the PE group, which is higher than the incidence reported in previous studies (ranging from $2 \%$ to $6 \%)(30,31)$, there was no significant difference compared with that in the non-PE group. To our knowledge, the timing of postoperative anticoagulation in patients with hip fracture and PE has never been established. The median time without anticoagulation after surgery was 2 days in our study, which suggests that it is relatively safe to resume anticoagulation therapy in the early phase.

Interestingly, preoperative IVC filter insertion did not affect the clinical course in the PE group. Although the use of IVF filters has increased over time (32), the role of IVC filters is still controversial especially in patients with VTE with anticoagulation therapy $(33,34)$. Moreover, potential adverse events might occur in patients with IVC filter insertion, including organ penetration, IVC thrombosis, device migration, and inability to retrieve the device $(35,36)$. However, IVC filter insertion might be beneficial in patients with hip fracture and acute PE. In our current study, the IVC filter group had a higher incidence of DVT than the non-IVC filter group, which might be related to the responsible surgeon's assumption that patients with DVT will benefit the most from the procedure. Previously, in 122 patients who underwent preoperative IVC filter insertion, Kim et al. reported that captured thrombus was identified in $13.1 \%$ of patients during the postoperative period (37). However, further studies will be needed to determine the role of IVC filter insertion in patients with hip fracture and acute PE.

The current study has several limitations. First, our study was retrospective in nature, and pulmonary CT angiography and lower-extremity venographic CT were not performed in some patients. In addition, our study was performed at a single tertiary referral center. These study characteristics might have introduced selection bias. However, the study population was followed up for $>3$ months, which enabled us to investigate the safety outcomes in these patients. Second, as the type of perioperative anticoagulation was diverse in the PE group, it is difficult to perform meaningful comparisons of anticoagulation agents. Third, only 1 patient had right ventricular dysfunction and 1 patient was classified as having PESI class $\mathrm{V}$ in the PE group. Thus, further studies in patients with high-risk PE are needed in the future. Despite these limitations, our study is the first to investigate the safety of early surgery in patients with hip fracture and PE, especially low- and intermediate-risk PE.

In conclusion, early surgery in patients with hip fracture and acute PE might be relatively safe and clinically feasible. Further prospective studies with larger populations will be needed to confirm our results.

\section{Acknowledgments}

Funding: This study was supported by the University of 
Ulsan College of Medicine.

\section{Footnote}

Conflicts of Interest: The authors have no conflicts of interest to declare.

Ethical Statement: The authors are accountable for all aspects of the work in ensuring that questions related to the accuracy or integrity of any part of the work are appropriately investigated and resolved. The study protocol was approved by the institutional review board of Asan Medical Center (approval no. 2019-0394), and written informed consent was waived owing to the retrospective nature of the study.

Open Access Statement: This is an Open Access article distributed in accordance with the Creative Commons Attribution-NonCommercial-NoDerivs 4.0 International License (CC BY-NC-ND 4.0), which permits the noncommercial replication and distribution of the article with the strict proviso that no changes or edits are made and the original work is properly cited (including links to both the formal publication through the relevant DOI and the license). See: https://creativecommons.org/licenses/by-nc-nd/4.0/.

\section{References}

1. Huang W, Goldberg RJ, Anderson FA, et al. Secular trends in occurrence of acute venous thromboembolism: the Worcester VTE study (1985-2009). Am J Med 2014;127:829-39.e5.

2. Huang D, Chan PH, She HL, et al. Secular trends and etiologies of venous thromboembolism in Chinese from 2004 to 2016. Thromb Res 2018;166:80-5.

3. Hong J, Lee JH, Yhim HY, et al. Incidence of venous thromboembolism in Korea from 2009 to 2013. PLoS One 2018;13:e0191897.

4. Kearon C, Akl EA, Ornelas J, et al. Antithrombotic therapy for VTE disease: Chest guideline and expert panel report. Chest 2016;149:315-52.

5. Farge D, Bounameaux H, Brenner B, et al. International clinical practice guidelines including guidance for direct oral anticoagulants in the treatment and prophylaxis of venous thromboembolism in patients with cancer. Lancet Oncol 2016;17:e452-e466.

6. Wendelboe AM, Raskob GE. Global burden of thrombosis: Epidemiologic aspects. Circ Res 2016;118:1340-7.
7. Gjonbrataj E, Kim JN, Gjonbrataj J, et al. Risk factors associated with provoked pulmonary embolism. Korean J Intern Med 2017;32:95-101.

8. Serhal M, Barnes GD. Venous thromboembolism: A clinician update. Vasc Med 2019;24:122-31.

9. Roberts TS, Nelson CL, Barnes CL, et al. The preoperative prevalence and postoperative incidence of thromboembolism in patients with hip fractures treated with dextran prophylaxis. Clin Orthop Relat Res 1990;(255):198-203.

10. Rosencher N, Vielpeau C, Emmerich J, et al. Venous thromboembolism and mortality after hip fracture surgery: the ESCORTE study. J Thromb Haemost 2005;3:2006-14.

11. Shin WC, Woo SH, Lee SJ, et al. Preoperative prevalence of and risk factors for venous thromboembolism in patients with a hip fracture: An indirect multidetector CT venography study. J Bone Joint Surg Am 2016;98:2089-95.

12. Jaffer AK, Brotman DJ, Chukwumerije N. When patients on warfarin need surgery. Cleve Clin J Med 2003;70:973-84.

13. O'Donnell M, Kearon C. Perioperative management of oral anticoagulation. Cardiol Clin 2008;26:299-309, viii.

14. Simunovic N, Devereaux PJ, Sprague S, et al. Effect of early surgery after hip fracture on mortality and complications: systematic review and meta-analysis. CMAJ 2010;182:1609-16.

15. Orosz GM, Magaziner J, Hannan EL, et al. Association of timing of surgery for hip fracture and patient outcomes. JAMA 2004;291:1738-43.

16. Jiménez D, Aujesky D, Moores L, et al. Simplification of the pulmonary embolism severity index for prognostication in patients with acute symptomatic pulmonary embolism. Arch Intern Med 2010;170:1383-9.

17. Konstantinides SV, Torbicki A, Agnelli G, et al. 2014 ESC guidelines on the diagnosis and management of acute pulmonary embolism. Eur Heart J 2014;35:3033-69, 3069a-3069k.

18. Douketis JD, Spyropoulos AC, Spencer FA, et al. Perioperative management of antithrombotic therapy: Antithrombotic therapy and prevention of thrombosis, 9th ed: American college of chest physicians evidence-based clinical practice guidelines. Chest 2012;141:e326S-e50S.

19. Young AM, Marshall A, Thirlwall J, et al. Comparison of an oral factor xa inhibitor with low molecular weight heparin in patients with cancer with venous thromboembolism: Results of a randomized trial (SELECT-D). J Clin Oncol 2018;36:2017-23. 
20. Lee JH, Hyun DG, Choi CM, et al. A retrospective study on efficacy and safety of rivaroxaban and dalteparin for long-term treatment of venous thromboembolism in patients with lung cancer. Respiration 2019;98:203-11.

21. Schulman S, Angeras U, Bergqvist D, et al. Definition of major bleeding in clinical investigations of antihemostatic medicinal products in surgical patients. J Thromb Haemost 2010;8:202-4.

22. EINSTEIN-PE Investigators, Büller HR, Prins MH, et al. Oral rivaroxaban for the treatment of symptomatic pulmonary embolism. N Engl J Med 2012;366:1287-97.

23. Eriksson BI, Lassen MR. Duration of prophylaxis against venous thromboembolism with fondaparinux after hip fracture surgery: a multicenter, randomized, placebo-controlled, double-blind study. Arch Intern Med 2003;163:1337-42.

24. Westrich GH, Rana AJ, Terry MA, et al. Thromboembolic disease prophylaxis in patients with hip fracture: a multimodal approach. J Orthop Trauma 2005;19:234-40.

25. Zahn HR, Skinner JA, Porteous MJ. The preoperative prevalence of deep vein thrombosis in patients with femoral neck fractures and delayed operation. Injury 1999;30:605-7.

26. Smith EB, Parvizi J, Purtill JJ. Delayed surgery for patients with femur and hip fractures-risk of deep venous thrombosis. J Trauma 2011;70:E113-6.

27. Lu Y, Ma B, Guo R, et al. Deep vein thrombosis in trauma: a prospective study of lower limb orthopedic trauma patients in Tianjin Hospital, China. Int Angiol 2007;26:165-70.

28. Cho YH, Byun YS, Jeong DG, et al. Preoperative incidence of deep vein thrombosis after hip fractures in Korean. Clin Orthop Surg 2015;7:298-302.

29. Grant PJ, Brotman DJ, Jaffer AK. Perioperative

Cite this article as: Kim HC, Park JH, Song JM, Hwang JJ, Hong SB, Oh YM, Lee SD, Lee JS. Safety of early orthopedic surgery in patients with intermediate/low- or low-risk pulmonary embolism. J Thorac Dis 2020;12(3):232-239. doi: $10.21037 /$ jtd.2020.01.54 anticoagulant management. Med Clin North Am 2009;93:1105-21.

30. McBane RD, Wysokinski WE, Daniels PR, et al. Periprocedural anticoagulation management of patients with venous thromboembolism. Arterioscler Thromb Vasc Biol 2010;30:442-8.

31. Spyropoulos AC, Douketis JD. How I treat anticoagulated patients undergoing an elective procedure or surgery. Blood 2012;120:2954-62.

32. Stein PD, Kayali F, Olson RE. Twenty-one-year trends in the use of inferior vena cava filters. Arch Intern Med 2004;164:1541-5.

33. Girard P, Stern JB, Parent F. Medical literature and vena cava filters: so far so weak. Chest 2002;122:963-7.

34. Decousus H, Leizorovicz A, Parent F, et al. A clinical trial of vena caval filters in the prevention of pulmonary embolism in patients with proximal deep-vein thrombosis. Prevention du risque d'embolie pulmonaire par interruption cave study group. N Engl J Med 1998;338:409-15.

35. Sarosiek S, Crowther M, Sloan JM. Indications, complications, and management of inferior vena cava filters: the experience in 952 patients at an academic hospital with a level I trauma center. JAMA Intern Med 2013;173:513-7.

36. Berczi V, Bottomley JR, Thomas SM, et al. Long-term retrievability of IVC filters: should we abandon permanent devices? Cardiovasc Intervent Radiol 2007;30:820-7.

37. Kim H, Han Y, Ko GY, et al. Clinical outcomes of a preoperative inferior vena cava filter in acute venous thromboembolism patients undergoing abdominalpelvic cancer or orthopedic surgery. Vasc Specialist Int 2018;34:103-8. 